\title{
Clinical-Epidemiological Characteristics That May Help the General Practitioner to Consider Covid-19 Diagnosis in Acute Respiratory Infections When Diagnostic Tests Are Not Accessible
}

\section{Turabian JL*}

Specialist in Family and Community Medicine, Regional Health Service of Castilla la Mancha (SESCAM), Spain

*Corresponding author: Jose Luis Turabian, Health Center Santa Maria de Benquerencia. Regional Health Service of Castilla la Mancha (SESCAM), Toledo, Spain, E-mail: jturabianf@ hotmail.com

\section{Research Article \\ Volume 4 Issue 2}

Received Date: April 09, 2020

Published Date: April 21, 2020

DOI: $10.23880 /$ eij-16000143

\section{Abstract}

Objective: To assess clinical-epidemiological characteristics that can help to consider the diagnosis of COVID-19 in acute respiratory infections when diagnostic tests are not available.

Methodology: A retrospective study was carried out on clinical and epidemiological variables in patients with symptoms of acute respiratory infection who consulted at a health center in Toledo, Spain, from March 9 to April 3, 2020. Patients were divided into two groups: with acute respiratory symptoms and diagnosis of COVID-19 using polymerase chain reaction (PCR); and 2) with acute respiratory symptoms and without COVID-19 PCR.

Results: Eighty patients were included, 18 in the COVID-19 positive group, and 62 patients with clinical symptoms of acute respiratory infection without COVID-19 test. In the group of patients diagnosed with COVID-19, the presence of fever, dyspnea, diarrhea, nausea / vomiting, signs of pneumonia, long duration of symptoms, being male, older than 65 years, being on previous treatment with angiotensin-converting-enzyme (ACE) inhibitors or angiotensin-receptor blockers (ARBs), presenting chronic diseases of the circulatory system, self-communication of possible contact with a COVID-19 patient, visiting the emergency services or the hospital, and being health personnel / working in healthcare settings, were statistically more frequent.

Conclusion: It is suggested that, in situations where the COVID-19 diagnostic test is not initially performed, when there was the presence of: 1) from the clinical point of view: fever, dyspnea, nausea / vomiting, or signs physical pneumonia, long duration of symptoms, in male patients or over 65 years; and / or 2) from the epidemiological point of view: previous treatment with ACE inhibitors or ARBs, presence of chronic diseases of the circulatory system, self-communication of possible contact with a COVID-19 patient, the visit to the services of emergency or hospital, or being a health professional / working in healthcare settings, patient should be considered as probable COVID-19, for the purposes of isolation, search for contacts, conducting a diagnostic PCR test, surveillance and treatment if appropriate.

Keywords: Coronavirus; COVID-19; SARS-CoV-2; General Practice; Epidemiology; Population Surveillance/methods; Public Health Practice 


\section{Epidemiology International Journal}

Abbreviations: PCR: Polymerase Chain Reaction; ACE: Angiotensin-Converting-Enzyme; ARBs: AngiotensinReceptor Blockers; SARS-Cov-2: Severe Acute Respiratory Syndrome Coronavirus 2; COVID-19: Coronavirus Disease 2019; GP: General Practitioner; WHO: World Health Organization.

\section{Introduction}

The current outbreak of coronavirus disease 2019 (COVID-19), caused by the severe acute respiratory syndrome coronavirus 2 (SARS-CoV-2) (1), continues to spread affecting many countries and territories around the world, with their figures rapidly changing. So it is a public health emergency of international concern. As of this writing, as of 5 de April de 2020, the pandemic has infected more than $1,000.000$ people and killed more than 60,000 worldwide; The United States has more than 277,000 cases and passed to China in the total number of COVID-19 cases, making it the country with most known cases worldwide [1-4]. The news from China, Iran, Italy, Spain, Estados Unidos and other areas hard hit by Coronavirus are chilling. Currently, it is recognized that transmission in new cases is already largely community-based. As the COVID-19 pandemic evolves, we gradually are accumulating knowledge to guide patient care. Although most disease is mild (80-85\%), $12-15 \%$ have a serious illness, and between $1-5 \%$ a potentially fatal disease, which can require intensive care for issues such as acute respiratory distress syndrome, shock, and multiorgan failure $[5,6]$.

Recognizing that lack of preparation for an outbreak is a major global health challenge, sharing knowledge on how to care for the minority of patients who become critically ill is important. But it is also very important how to deal with infection in primary care and in the community, which means attending to most cases. For most illnesses the general practitioner (GP) is the first point of contact in the health care system and he/she is in a rare position that combines the individual and community dimensions, which has implications in the diagnosis and management of patients with COVID -19 [7-11]. In this sense, World Health Organization (WHO) head Tedros Adhanom Ghebreyesus said there has not been an urgent enough escalation in testing, isolation and contact tracing, which should be the "backbone" of the global response. He said it is not possible to "fight a fire blindfolded", and social distancing measures and hand washing will not alone extinguish the epidemic. So, a test on each suspected case should be done [12].

However, this advice is not carried out in practice in many places and for various reasons, including the lack of sufficient tests. Thus, the failure to perform a diagnostic test in patients with mild respiratory symptoms in the community, as in Spain (since the instructions are, as of April 4, 2020, that the diagnostic test for SARS-CoV-2 be carried out In people with an acute clinical picture, respiratory infection admitted to hospital, or respiratory infection of any degree in health personnel, and similarly, no routine diagnostic tests are performed on contacts), leads to a situation of uncertainty in the GP before patients with symptoms of acute respiratory infection [11].

Limited information is available to characterize the spectrum of clinical symptoms associated with COVID-19. Clinical, epidemiological, and field studies are likely to need improvement, and simple community studies are lacking so that rapid decisions can be made for diagnosis and treatment in COVID-19. A "living epidemiology" is needed to help make public health measures and also, decisions in general medicine in real time. In this scenario, a small study is presented, carried out in a community facing the urgency of the exponential increase in COVID-19, which aims to assess the clinical-epidemiological characteristics that can help the general practitioner to consider the diagnosis of COVID-19 in acute respiratory infections, when diagnostic tests are not available for all patients.

\section{Material and Methods}

A retrospective study was carried out on some clinical and epidemiological variables, based on the medical records, of the patients with symptoms of acute respiratory infection who consulted in a general medicine consultation in the Santa Maria de Benquerencia Health Center, Toledo, Spain, which has a list of 2,000 patients> 14 years of age (in Spain GPs care for people> 14 years of age), from March 9, 2020 (on that date, 26 official cases of COVID-19 were reported in the Castilla-La Mancha region, which has a population of 2,035,505 inhabitants, whose capital is Toledo with 84873 , and it is from that day when official statistics indicate an exponential increase in new cases) to April 3, 2020 (date the case growth curve began to flatten) (Figure 1).

Sample size was calculated for exposure to prior contact with patients with proven or probable COVID-19 in two groups: 1) patients with symptoms of acute respiratory infection and positive COVID-19 test, and 2) patients with clinical symptoms of respiratory infection but no test performed, for a Two-sided Confidence Level (1-alpha) of 95, a Power (\% probability of detection) of 80, a Ratio of group 2 patients per group 1 patients of 3 , a Hypothetical proportion of group 2 patients with $15 \%$ exposure, and a hypothetical proportion of group 1 patients with $50 \%$ exposure. So, the sample size should be, at least, of 54 patients, 14 in the group 1 patients, and 40 in group 2 patients [13]. 


\section{Epidemiology International Journal}

\section{FIGURE 1. CHRONOLOGY OF COVID-19 OFFICIAL CASES IN CASTILLA-LA MANCHA (SPAIN)}

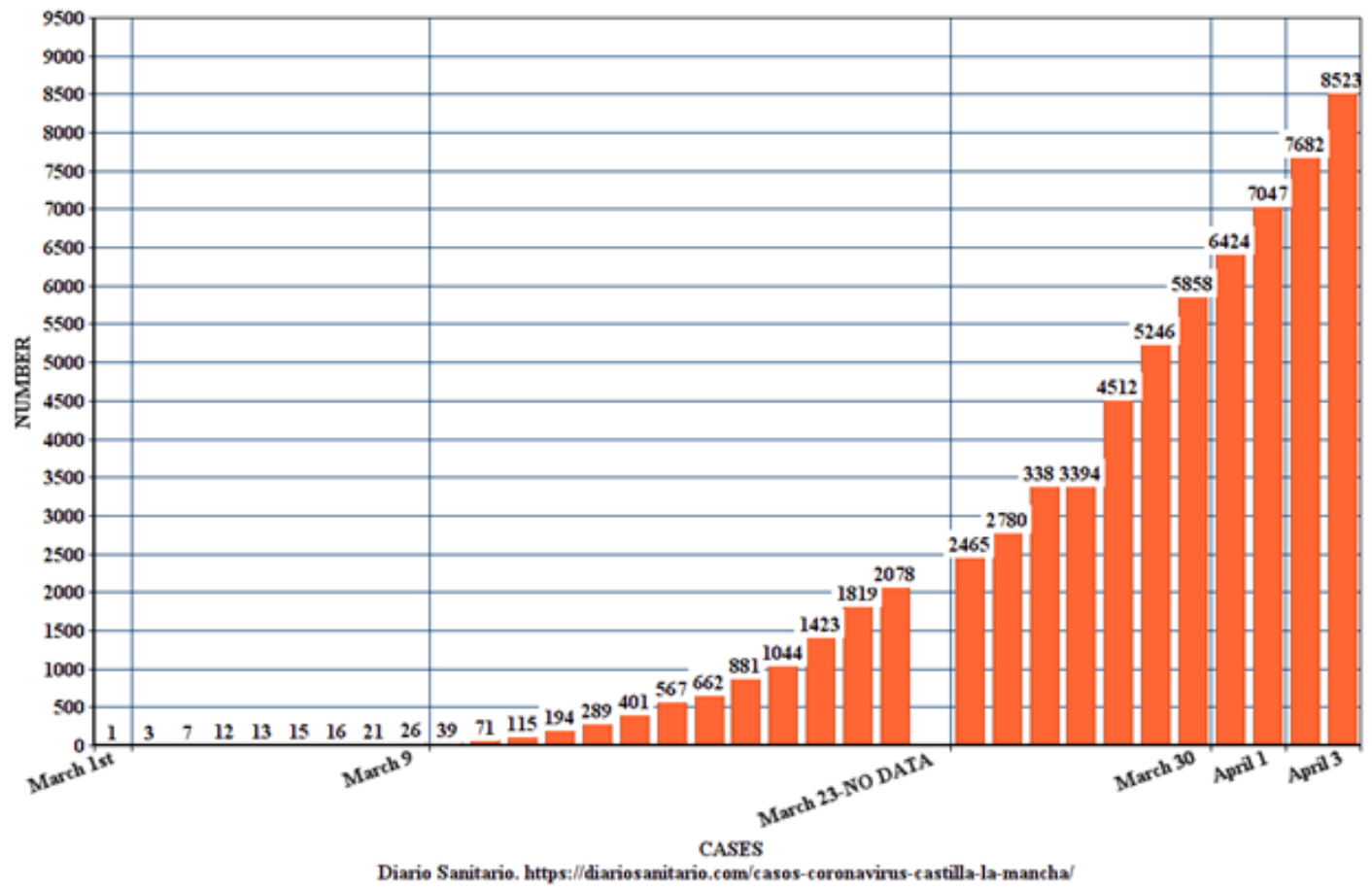

Figure 1: Chronology of Covid-19 Official Cases in Castilla-La Mancha (Spain) During Study Dates.

The patients in the group without test for SARS-CoV-2 (group 2 patients) were all patients seen in the consultation mentioned during the study period. The patients in the COVID-19 group (group 1 patients) were also all patients with this characteristic seen at that time in the consultation, but their number was completed with 9 patients randomly selected from other consultations at the same health center. Therefore, for analysis, the patients were divided into two groups: 1) group 1 patients: patients with acute respiratory symptoms and diagnosis of COVID-19 using polymerase chain reaction (PCR), and 2) group 2 patients: patients with acute respiratory symptoms and no COVID-19 PCR performed.

The following variables were collected: sex, age, cough, fever, dyspnoea, odynophagia, dysgeusia-anosmia, headache, diarrhea, insomnia, general pains, asthenia, nausea-vomiting, pneumonia, hospitalization-Visit to the Hospital Emergency Department, confirmed or probable COVID-19 contact, healthcare professional / Working in a healthcare facility, exitus, angiotensin-converting-enzyme (ACE) inhibitors or angiotensin-receptor blockers (ARBs) treatment, sick leave, days duration of symptoms, and chronic disease (defined as "any alteration or deviation from normal that has one or more of the following characteristics: is permanent, leaves residual impairment, is caused by a nonreversible pathological alteration, requires special training of the patient for rehabilitation, and / or can be expected to require a long period of control, observation or treatment" [14-16], classified according to the International Statistical Classification of Diseases and Health-Related Problems, CD-10 Version of 2019 [17]. Bivariate comparisons were performed, using the Chi Square test for percentages, with Yates correction, vs Fisher's Exact Probability when indicated, and the Student $t$ test for the mean.

\section{Results}

Eighty patients were included, 18 in the COVID-19 positive group (group 1 patients), and 62 patients with clinical symptoms of acute respiratory infection without COVID-19 test (group 2 patients). (Tables $1 \& 2$ ), and (Figure 2) show the results for the clinical and epidemiological factors. In the group of patients with a diagnosis of COVID-19 (group 1 patients) vs. patients with acute respiratory symptoms but without a diagnostic test performed (group 2 patients), the presence of fever, dyspnea, diarrhea, nausea / vomiting, signs of pneumonia, long duration of symptoms, being male, over 65 years of age, having been previously treated with 


\section{Epidemiology International Journal}

ACE inhibitors or ARBs, presenting chronic diseases of the circulatory system, self-communication of possible contact with a COVID-19 patient, visit to the emergency services or the hospital, and being healthcare personnel or working in healthcare settings, were variables statistically more frequent. In group 2 there were 4 exitus (22\%).

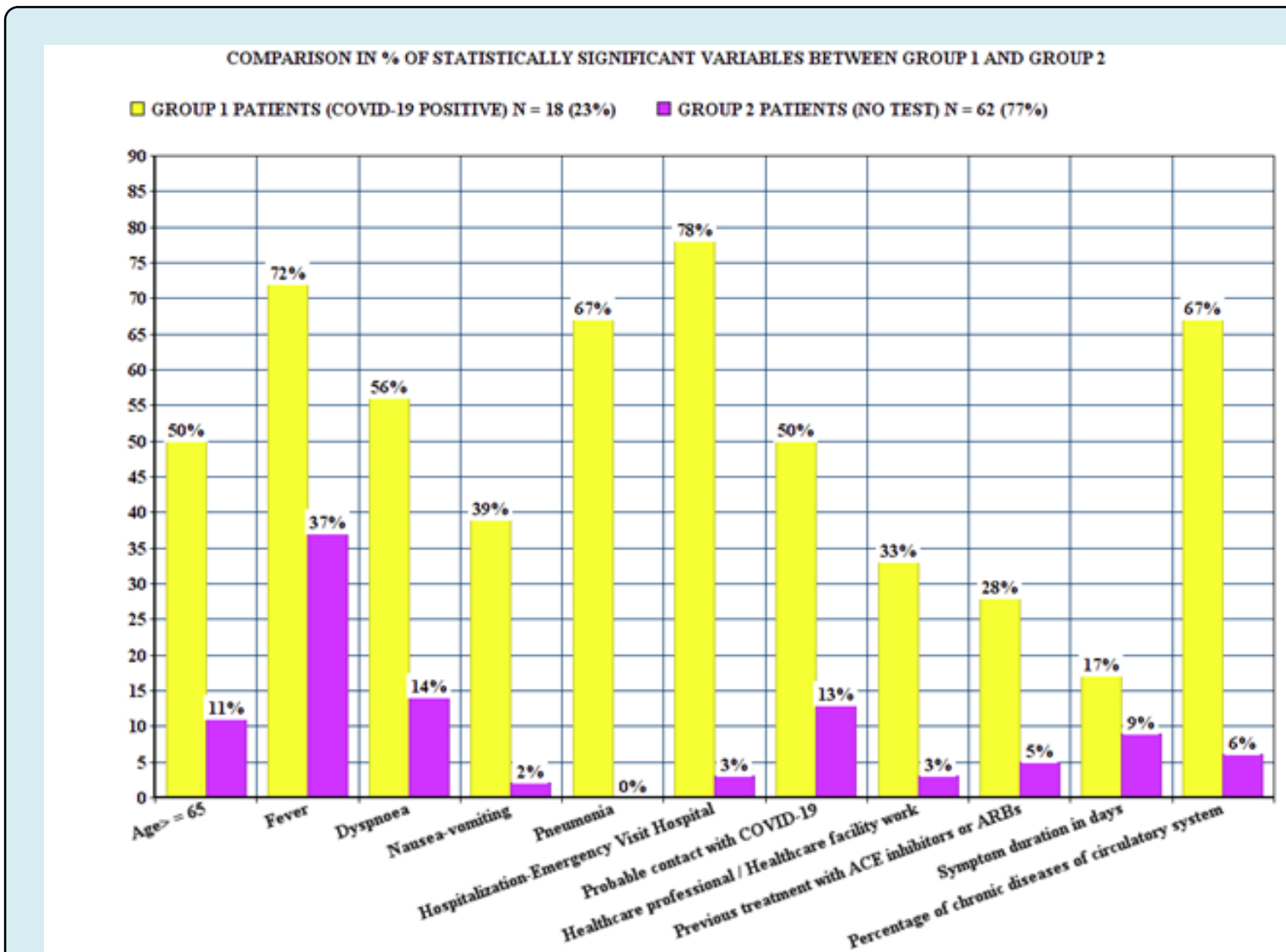

Figure 2: Comparison in \% of Statistically Significant Variables between Group 1 and Group 2.

\begin{tabular}{|c|c|c|c|}
\hline $\begin{array}{l}\text { VARIABLES: } \mathrm{N}=800 \\
\text { indicates } \%\end{array}$ & $\begin{array}{l}\text { GROUP } 1 \text { PATIENTS } \\
\text { (COVID-19 POSITIVE) } \\
\mathrm{N}=18(23)\end{array}$ & $\begin{array}{l}\text { GROUP } 2 \text { PATIENTS } \\
\text { (NO TEST) } \mathrm{N}=62 \\
\text { (77) }\end{array}$ & $\begin{array}{l}\text { STATISTICAL SIGNIFICANCE NS indicates not } \\
\text { significant }\end{array}$ \\
\hline Males & $13(72)$ & $31(50)$ & $\mathrm{X} 2=2.7834 . \mathrm{p}=.095246 . \mathrm{NS}$ at $\mathrm{p}<.05$ \\
\hline Age $>=65$ & $9(50)$ & $7(11)$ & $\mathrm{X} 2=13.0645 . \mathrm{p}=.000301$. Significant at $\mathrm{p}<.05$. \\
\hline Cough & $17(94)$ & $60(97)$ & Fisher exact test $=0.5397 . \mathrm{NS}$ at $\mathrm{p}<.05$ \\
\hline Fever & $13(72)$ & $23(37)$ & $\mathrm{X} 2=6.9541 . \mathrm{p}=.008363$. Significant at $\mathrm{p}<.05$. \\
\hline Dyspnoea & $10(56)$ & $9(14)$ & $\mathrm{X} 2=12.974 . \mathrm{p}=.000316$. Significant at $\mathrm{p}<.05$. \\
\hline Odynophagia & 0 & $7(11)$ & Fisher exact test $=0.34 . \mathrm{NS}$ at $\mathrm{p}<.05$ \\
\hline Dysgeusia-anosmia & $3(17)$ & $4(6)$ & Fisher exact test $=0.1852$. NS at $\mathrm{p}<.05$ \\
\hline Headache & $1(6)$ & $6(10)$ & Fisher exact test $=1$. NS at $\mathrm{p}<.05$ \\
\hline Diarrhea & 0 & $7(11)$ & Fisher exact test $=0.34 . \mathrm{NS}$ at $\mathrm{p}<.05$ \\
\hline Insomnia & $1(6)$ & 0 & Fisher exact test $=0.225 . \mathrm{NS}$ at $\mathrm{p}<.05$ \\
\hline General pains & $5(28)$ & $14(23)$ & $\begin{array}{c}\text { Chi-square with Yates correction }=0.02 . \mathrm{p}= \\
.887427 . \mathrm{NS} \text { at } \mathrm{p}<.05 .\end{array}$ \\
\hline
\end{tabular}




\begin{tabular}{|c|c|c|c|}
\hline Asthenia & $4(22)$ & $4(6)$ & Fisher exact test $=0.0713$. NS at $\mathrm{p}<.05$ \\
\hline Nausea-vomiting & $7(39)$ & $1(2)$ & Fisher exact test $=0.0001$. Significant at $\mathrm{p}<.05$. \\
\hline Pneumonia & $12(67)$ & 0 & Fisher exact test $<0.00001$. Significant at $\mathrm{p}<.05$. \\
\hline $\begin{array}{c}\text { Hospitalization- } \\
\text { Emergency Visit } \\
\text { Hospital } \\
\end{array}$ & $14(78)$ & $2(3)$ & $\begin{array}{c}\text { Chi-square with Yates correction }=43.9113 . \mathrm{P}< \\
0.00001 \text {. Significant at } \mathrm{p}<.05\end{array}$ \\
\hline $\begin{array}{l}\text { Probable contact with } \\
\text { COVID-19 }\end{array}$ & $9(50)$ & $8(13)$ & $\begin{array}{c}\text { Chi-square with Yates correction is 9.3622. } \mathrm{p}= \\
.002215 . \text { Significant at } \mathrm{p}<.05 .\end{array}$ \\
\hline $\begin{array}{c}\text { Healthcare } \\
\text { professional / } \\
\text { Healthcare facility } \\
\text { work }\end{array}$ & $6(33)$ & $2(3)$ & Fisher exact test $=0.0013$. Significant at $\mathrm{p}<.05$. \\
\hline $\begin{array}{c}\text { Previous treatment } \\
\text { with ACE inhibitors or } \\
\text { ARBs }\end{array}$ & $5(28)$ & $3(5)$ & Fisher exact test $=0.0125$. Significant at $\mathrm{p}<.05$. \\
\hline Sick leave & $5(28)$ & $20(32)$ & Chi-square $=0.1303 . \mathrm{p}=.718084 . \mathrm{NS}$ at $\mathrm{p}<.05$ \\
\hline $\begin{array}{l}\text { Symptom duration in } \\
\text { days (Range) }\end{array}$ & 17 (4-30 días) & 9 (3-25 días) & $\begin{array}{c}\mathrm{t} \text {-value }=4.90534 . \mathrm{p}<.00001 . \text { Significant at } \mathrm{p}< \\
.05 .\end{array}$ \\
\hline
\end{tabular}

Table 1: Comparison Between Patients With Symptoms Of Acute Respiratory Infection Who Consult In General Medicine From March 9, 2020 Through April 3, 2020: Group 1-Patients With Covid-19 Positive Vs. Group 2-Patients With Not Testing For Covid-19.

\begin{tabular}{|c|c|c|c|}
\hline $\begin{array}{c}\text { DISEASES } \\
\text { ACCORDING TO } \\
\text { WHO, ICD-10 } \\
\text { GROUPS }(\text { ) indicates } \\
\% \\
\end{array}$ & $\begin{array}{c}\text { GROUP } 1 \text { PATIENTS: NUMBER } \\
\text { OF CHRONIC DISEASES IN } \\
\text { PATIENTS WITH COVID-19 } \\
\mathrm{N}=18(23)\end{array}$ & $\begin{array}{c}\text { GROUP } 2 \text { PATIENTS: } \\
\text { NUMBER OF CHRONIC } \\
\text { DISEASES IN } \\
\text { PATIENTS SIN TEST } \\
\text { N=62 (77) }\end{array}$ & $\begin{array}{l}\text { STATISTICAL SIGNIFICANCE NS } \\
\text { indicates not significant }\end{array}$ \\
\hline -II Neoplasms & 0 & $2(3)$ & Fisher exact test $=1 . \mathrm{NS}$ at $\mathrm{p}<.05$ \\
\hline -IV Endocrine & $5(28)$ & $16(26)$ & $\begin{array}{l}\mathrm{X} 2 \text { with Yates correction }=0.0187 . \mathrm{NS} \text { at } \\
\mathrm{p}<.05 .\end{array}$ \\
\hline -V Mental & $4(22)$ & $10(16)$ & $\begin{array}{l}\mathrm{X} 2 \text { with Yates correction }=0.0608 \text {. NS at } \\
\mathrm{p}<.05\end{array}$ \\
\hline $\begin{array}{l}\text {-VI-VIII Nervous and } \\
\text { senses }\end{array}$ & $1(6)$ & $8(13)$ & Fisher exact test $=0.6755$. NS at $\mathrm{p}<.05$. \\
\hline $\begin{array}{l}\text {-IX Circulatory } \\
\text { system }\end{array}$ & $12(67)$ & $4(6)$ & $\begin{array}{c}\mathrm{X} 2 \text { with Yates correction }=27.9615 . \mathrm{p}< \\
0.00001 . \text { Significant at } \mathrm{p}<.05 .\end{array}$ \\
\hline $\begin{array}{l}\text {-X Respiratory } \\
\text { system }\end{array}$ & $3(17)$ & $12(19)$ & $\begin{array}{l}\mathrm{X} 2 \text { with Yates correction }=0.0074 . \mathrm{NS} \text { at } \\
\mathrm{p}<.05 .\end{array}$ \\
\hline -XI Digestive system & $3(17)$ & $4(6)$ & Fisher exact test $=0.1852$. NS at $\mathrm{p}<.05$. \\
\hline $\begin{array}{c}-\mathrm{XII} \text { Diseases of the } \\
\text { skin }\end{array}$ & 0 & $1(2)$ & Fisher exact test $=1$. NS at $\mathrm{p}<.05$. \\
\hline $\begin{array}{l}\text {-XIII Musculo- } \\
\text { skeletal }\end{array}$ & $3(17)$ & $6(10)$ & Fisher exact test $=0.4131$. NS at $\mathrm{p}<.05$. \\
\hline -XIV Genitourinary & $4(22)$ & $5(8)$ & Fisher exact test $=0.1093$. NS at $\mathrm{p}<.05$. \\
\hline
\end{tabular}

Table 2: Number Of Chronic Diseases According To Who, Icd-10 Groups On Patients With Covid-19 (Group 1 Patients) And Patients Sin Test (Group 2 Patients). 


\section{Epidemiology International Journal}

\section{Discussion}

The great epidemics do not arise from an event similar to the "Big Bang", but they develop slowly underground and apparently only become visible when the exponential explosion of cases occurs [18]. It has been reported [19] that almost $80 \%$ of the cases diagnosed in China before the confinement by COVID-19 started on January 23 would have been infected by undocumented cases (not known), for having little or no symptoms. Previously, various articles in notable magazines pointed in that direction [20-24].

The WHO has repeatedly expressed "a simple message for all countries: test, test, and test. Test every suspected case. If they test positive, isolate them and find out who they have been in close contact with up to 2 days before they developed symptoms, and test those people too" [12]. Although the GP has a certain "situational awareness" regarding the cases of disease in general population in the community and in his / her list of patients, including the rate of hidden or undiagnosed cases, however, the failure to perform the diagnostic test of COVID-19 on patients with respiratory symptoms in the community, like is the case in Spain (since the instructions are, as of March 18, 2020, that diagnostic test for SARSCoV-2 be performed at people with a clinical picture of acute respiratory infection admitted to the hospital, or respiratory infection of any degree in health personnel. Similarly, routine diagnostic tests are not performed on contacts), leads the GP to a clinical and epidemiological ignorance and uncertainty [11].

In Spain, with a scenario on March 18, 2020, of widespread sustained transmission, and with more than 13,716 positives and 558 deaths, making it the second country in the world that registers more new cases every day, according to the health authorities, and flattening the curve and, therefore, preventing many people from becoming infected at the same time is the main objective so as not to saturate the health system; In this date, the virus is in Spain in exponential growth phase and shows a rate similar to that of Italy. Also this increase is in the different Spanish autonomous communities, although have an uneven distribution, including that of Castilla-La Mancha $[25,26]$.

Since the tests are not available to everyone, the data do not accurately reflect the extent of transmission in communities around the world. For Spain, the official incidence figures (11,000 positive as of March 18, 2020) are therefore false; perhaps, one could speak of "minimal incidence." In fact, the only most reliable epidemiological figure is mortality or case fatality [27]. In this way, experts calculate, with respect to Castilla-La Mancha (Spain), with 567 official cases and 17 deaths, would have 13,600 real cases (as of March 16). In the same way, it could be calculated that in the list of patients of a GP (with an average of 2000 patients) there could be of the order of 26 cases, although the vast majority without diagnostic because of no diagnostic tests were performed [11].

In this context, it is difficult to differentiate by clinical data the main diseases that cause acute respiratory infection. However, it would be very useful to have some clinicalepidemiological guidance, in the situation of absence of diagnostic tests or restrictions on their use, in order to identify the patients who are most likely to have COVID-19, vs. influenza or the common cold, for in these cases to carry out a PCR test, and / or initiate early isolation measures, contact identification, monitoring of the evolution of the disease and treatment in the community or sending to the hospital if it is indicated.

The clinical spectrum of COVID-19 varies from:

- Asymptomatic or paucisymptomatic forms

- Cases with mild-severe disease with non-pneumonia and mild pneumonia ( $80 \%$ of cases), whose symptoms and evolutionary course can be described by the patient as follows: "... a cluster of symptoms that made me feel like I had been hit by a bus ... It was a combination of things, including aches and pain in my muscles and joints, a fever, and a high temperature, and I really couldn't do much or move much .... The worst symptoms were yet to come. After 4 days, I began to feel tightness in his chest and breathlessness, along with a nasty dry cough that would not go away.... The horrible feeling of being unwell continued, along with dizziness. There were times during this period that I thought I might require hospital treatment.... Although I was trying to eat what could, I experienced a sharp drop in appetite, along ... the loss of sense of taste and smell. On around day 7, the symptoms began to ease, and I thought he was over the worst of the infection. However, just a couple of days later, the shortness of breath began to return, as did the tightness in his chest. The cough, which had not properly gone away, began to get worse again ... I was very worried that I was getting worse. It is difficult to know when to seek further help. However, because I began to feel better again after this, I didn't think I would need to go into hospital... Now more than 2 weeks later, I've been able to to return to work and the infection has run its course"

- Critical clinical conditions characterized by respiratory failure [28-32].

Patients in the COVID-19 positive group (group 1 patients) were older and predominantly males. These characteristics coincide with what has been described [2832]. Radiological examinations have become vital in early diagnosis and assessment of disease course. So, computed 


\section{Epidemiology International Journal}

tomography scans findings have been recommended as best evidence for clinical diagnosis of COVID-19 in Hubei, China $[33,34]$. Similarly, in our study, the presence of pneumonia was an important finding that differentiated COVID-19 (group 1 patients) from other acute respiratory infections (group 2 patients).

On the other hand, in our study the presence of dysgeusiaanosmia was not found more frequently in the COVID-19 group, although this symptom has been noted in the literature. Although it is a frequent symptom in the general population [35], it is admitted that, if there is lose of sense of smell and there are other symptoms concerning for COVID-19 (fever, cough, shortness of breath), and it cannot identify another reasonable cause of anosmia (like seasonal allergies), then the loss of smell may be another symptom of COVID-19 $[36,37]$. Gastrointestinal symptoms are common in patients with COVID-19, mainly diarrhoea and nausea-vomiting [38]. We found a higher frequency of nausea-vomiting in COVID-19 vs. acute respiratory infections without test for COVID-19. In another sense, older age and comorbidities have consistently been reported as risk factors for unfavorable prognosis. Thus, higher mean age and higher prevalence of comorbidities in western countries may explain the considerable COVID19-associated mortality seen there currently [39]. Several reports have shown specific comorbidities associated with an increased risk of infection, being the most common the cardiovascular (hypertension, coronary heart disease and cerebrovascular disease) and diabetes [40]. This fact also appears in our study

In short, our study shows a series of clinical and epidemiological characteristics that can significantly suggest that it is a case of COVID-19, without having carried out the diagnostic test, which can help the GP to make subsequent decisions, in contexts of limitation of PCR tests. Although cough and fever are two symptoms that exist in all the most frequent acute respiratory infections, the presence of dyspnea, nausea-vomiting, pneumonia, and a duration of symptoms of more than 7 days, previous treatment with ACE inhibitors or ARBs, presenting chronic diseases of the circulatory system, self-communication of possible contact with a COVID-19 patient, visiting the emergency services or the hospital, or being health personnel / working in healthcare settings, suggest COVID-19.

We found a higher frequency of previous treatment with ACE inhibitors or ARBs. Researchers proposed that could increase the risk for developing severe COVID-19. The coronavirus binds to target cells through ACE 2, the expression of which is increased when patients take these drugs. However, there is no clinical data to support that this is actually true, and so, patients with COVID-19 who have underlying hypertension, heart failure, or ischemic heart disease should not stop taking their ACE inhibitors or ARBs, according to a new statement from the American Heart Association, the American College of Cardiology, and the Heart Failure Society of America, the European Society on Hypertension, and the Council on Hypertension of the European Society of Cardiology [40-42]. However, our data supports the relationship between ACE inhibitors or ARBs and COVID-19, and this fact needs more research [40].

Our study also points out the relationship between the diagnosis of COVID-19 and being treated in the hospital emergency department or being admitted to the hospital. Of course, this relationship is obvious, since the COVID-19 PCR was only performed in the hospital, and in addition, patients who go to the emergency department or are hospitalized are most likely the most serious. But, our results suggest that we should not lose sight of the fact that at the beginning of the pandemic, hospitals, emergency departments, general medicine consultations and nursing homes, were exposed to asymptomatic, or with few symptoms, or very symptomatic patients but at a time when COVID-19 was not considered, and protective equipment was not used or it was not available, and perhaps not even masks and gloves, so all these environments and all the sanitary and auxiliary personnel of these centers became vectors of the disease for other outpatients, hospitalized patients, and contacts of these and health personnel. So, hospitals, nursing homes and health centers (to a lesser extent) are "biological bombs" that act as vectors of disease, and in this sense it has been described that hospitals might be the main COVID-19 carriers $[43,44]$.

In summary, although the correct practice in the community, in the epidemic of COVID-19, should be the performance of "test, test, and test" [12], in the reality of contexts with absence or limitations of use of PCR tests, it can be difficult to differentiate diseases that present as acute respiratory infections in adults. Although one possibility is to consider all respiratory symptoms as COVID-19, this approach, if prolonged in time, produces a great overload of the primary care system that is unsustainable.

The decision to administer the COVID-19 test should be based on clinical judgment, along with the presence of compatible signs and symptoms. It has been recommended that COVID-19 be considered as [45]:

1. Priority 1 to ensuring optimal care options for all hospitalized patients, lessen the risk of nosocomial infections, and maintain the integrity of the healthcare system, in hospitalized patients, symptomatic healthcare workers

2. Priority 2 to ensuring that those who are at highest risk of complication of infection are rapidly identified and appropriately triaged (patients in long-term care facilities with symptoms, patients 65 years of age and older with 


\section{Epidemiology International Journal}

symptoms, patients with underlying conditions with symptoms, first responders with symptoms)

3. And priority 3 as resources allow, for testing individuals in the surrounding community of rapidly increasing hospital cases to decrease community spread, and ensure health of essential workers (critical infrastructure workers with symptoms, individuals who do not meet any of the above categories with symptoms, health care workers and first responders, individuals with mild symptoms in communities experiencing high COVID-19 hospitalizations.

So, based on what was reported in the literature about the COVID-19 clinic, and our results, some differential diagnostic criteria could be proposed for COVID-19, influenza and the common cold in general medicine (Table 3) [46-49].

\begin{tabular}{|c|c|c|}
\hline \multicolumn{2}{|c|}{ PROPOSED APPROACH ABOUT DIFFERENCES OF THE THREE MOST FREQUENT RESPIRATORY INFECTIONS IN } \\
ADULTS
\end{tabular}

Table 3: Proposed Approach about Differences of the Three Most Frequent Respiratory Infections in Adults.

\section{Limitations and Strong Points of the Study}

Of course, this is a small study, carried out in the context of the health emergency of the COVID-19 pandemic, and its results should be considered as suggestions and hypotheses to prove or refute. The fact that in the group without diagnostic test for COVID-19 there was probably also some case of COVID-19 is a limitation in the comparison of the variables studied and same real differences may have been masked. It has been reported that $5 \%$ of patients who presented to the emergency department with a mild illness similar to the influence between March 12 and 15, tested positive for SARS-CoV-2 [50]. Thus, it can be thought that in our group of 62 patients with symptoms of acute respiratory infection without a diagnostic test for COVID-19, 3 of them (5\%) could actually be COVID-19. But, at the same time, this fact makes the variables that do show differences, these are more likely true and credible.

\section{Conclusion}

Although it is highly desirable to carry out diagnostic tests on all patients suspected of COVID-19 and their contacts, in practice contexts may be found in which the availability of such tests is limited or does not exist. In these scenarios, certain clinical-epidemiological criteria may be useful to differentiate COVID-19 from other acute respiratory infections. Our results suggest that, in situations where the COVID-19 diagnostic test is not initially performed, when there are:

1. From the clinical point of view: the presence of fever, dyspnea, diarrhea, nausea / vomiting, or physical signs of pneumonia, with long duration of symptoms, in male patients or over 65 years

2. And/or from the epidemiological point of view: the previous treatment with ACE inhibitors or ARBs, the presence of chronic diseases of the circulatory system, the self-communication of possible contact with a COVID-19 patient, the visit to the services of emergency or hospital, or being health personnel / working in healthcare settings

These patients should be considered as probable patients with COVID-19, for the purposes of isolation, search for contacts, conducting a diagnostic PCR test, surveillance and treatment if appropriate. On the contrary, in situations where the diagnostic test is not accessible initially, if any of these factors do not concur (young patients, women, without 


\section{Epidemiology International Journal}

the clinical or epidemiological data previously described), it is probably first of all necessary to think of another cause of the symptoms of acute respiratory infection, other than COVID-19. On the other hand, it is suggested that health workers are important vectors of infection, and health centers (hospitals, health centers, nursing homes), in the current architectural and organizational configuration, are biological pumps that contribute very significantly to the growth of the epidemic.

Finally, It is suggested that the hypotheses resulting from this small study could be worthy of further research to verify or refute them.

\section{References}

1. Wei X, Li X, Cui J (2020) Evolutionary Perspectives on Novel Coronaviruses Identified in Pneumonia Cases in China. National Science Review 7(2): 239-242.

2. Editorial (2020) COVID-19, a pandemic or not? Lancet Infect Dis 20(4): 383.

3. COVID-19 Coronavirus Outbreak

4. Coronavirus COVID-19 Global Cases by the Center for Systems Science and Engineering (CSSE) at Johns Hopkins. The Center for Systems Science and Engineering (CSSE) at JHU.

5. Wu Z, McGoogan JM (2020) Characteristics of and important lessons from the coronavirus disease 2019 (COVID-19) outbreak in China: summary of a report of 72314 cases from the Chinese Center for Disease Control and Prevention. JAMA 323(13): 1239-1242.

6. Baud D, Qi X, Nielsen SK, Musso D, Pomar L, et al. (2020) Real estimates of mortality following COVID-19 infection. Lancet Infect Dis.

7. Smith J, Sears N, Taylor B, Johson M (2020) Serious games for serious crises: reflections from an infectious disease outbreak matrix game. Global Health 16(18).

8. Turabian JL (2017) The Variation of Seasonal Diseases in Family Medicine Depends on Infectious Diseases and these are Mainly Respiratory Diseases. J Gen Pract (Los Angel) 5: 309 .

9. Turabian JL (2017) Prevalence of Chronic Diseases: in Defence of Epidemiological Craftsmanship in Family Medicine. CP Epidemiology 1(1): 005.

10. Turabian JL (1995) Cuadernos de Medicina de Familia y Comunitaria. Una introduccion a los principios de Medicina de Familia. [Notebooks of Family and
Community Medicine. An introduction to the principles of Family Medicine] Madrid Diaz de Santos 1: 576.

11. Turabian JL (2020) Micro-impact of the pandemic by covid-19 in the general medicine. Clinical and epidemiological reflections from the situation in spain march 2020. Epidemol Int J 4(2): 1-11.

12. WHO (2020) WHO Director-General's opening remarks at the media briefing on COVID-19; 16 March.

13. Open Source Epidemiologic Statistics for Public Health.

14. Strauss AL (1984) Chronic illness and the quality of life. St Louis: The C.V. Mosby Company.

15. Gill M (2017) Augmented care: An alternative model of care for people with chronic disease. Int J Care Coord 20(1-2): 5-7.

16. Calderon LA, Vetrano DL, Onder G, Gimeno FLA, Coscollar SC, et al. (2017) Assessing and Measuring Chronic Multimorbidity in the Older Population: A Proposal for Its Operationalization. J Gerontol A Biol Sci Med Sci 72(10): 1417-1423.

17. WHO (2019) International Statistical Classification of Diseases and Health-Related Problems. ICD-10 Version: 2019.

18. Zhang X (2020) Epidemiology of Covid-19. N Engl J Med.

19. Li R, Pei S, Chen B, Song Y, Zhang T, et al. (2020) Substantial undocumented infection facilitates the rapid dissemination of novel coronavirus (SARS-CoV2). Science eabb3221.

20. Bai Y, Yao L, Wei T (2020) Presumed Asymptomatic Carrier Transmission of COVID-19. JAMA 323(14): 14061407.

21. Rothe C, Schunk M, Sothmann P, Bretzel G, Froeschl G, et al. (2020) Transmission of 2019-nCoV Infection from an Asymptomatic Contact in Germany. N Engl J Med 382: 970-971.

22. Hu Z, Song C, Xu C, Jin G, Chen Y, et al. (2020) Clinical characteristics of 24 asymptomatic infections with COVID-19 screened among close contacts in Nanjing, China. Sci China Life Sci.

23. Han Y, Yang H (2020) The transmission and diagnosis of 2019 novel coronavirus infection disease (COVID-19): A Chinese perspective. J Med Virol: 1-6.

24. Turabian JL (2020) Medical concepts with clinicalepidemiological implications that have to be re-assessed 
from the COVID-19 pandemic. International Journal of General Practice.

25. Consejería de Sanidad. Castilla-La Mancha. Spain.

26. Diario Sanitario.

27. Backhaus A (2020) Coronavirus: Why it's so deadly in Italy. Demographics and why they are a warning to other countries.

28. Kirby T (2020) UK senior police officer with COVID-19. Lancet Respir Med.

29. (2020) Symptoms of Coronavirus. CDC.

30. Cascella M, Rajnik M, Cuomo A, Dulebohn SC, Napoli RD (2020) Features, Evaluation and Treatment Coronavirus (COVID-19). StatPearls [Internet]. Treasure Island (FL): StatPearls Publishing.

31. Rothan HA, Byrareddy SN (2020) The epidemiology and pathogenesis of coronavirus disease (COVID-19) outbreak. J Autoimmun 109: 102433.

32. Lescure FX, Bouadma L, Nguyen D, Parisey M, Wicky $\mathrm{PH}$, et al. (2020) Clinical and virological data of the first cases of COVID-19 in Europe: a case series. Lancet: 1-10.

33. Zu ZY, Jiang MD, Xu PP, Chen W, Ni QQ et al. (2020) Coronavirus Disease 2019 (COVID-19): A Perspective from China. Radiology.

34. Huang C, Wang Y, Li X, Ren L, Zhao J, et al (2020) Clinical features of patients infected with 2019 novel coronavirus in Wuhan, China. Lancet 395(10223): 497-506.

35. Liu G, Zong G, Doty RL, Sun Q (2016) Prevalence and risk factors of taste and smell impairment in a nationwide representative sample of the US population: a crosssectional study. BMJ Open 6(11): 013246.

36. Loss of sense of smell as marker of COVID-19 infection (2020) ENTUK.

37. Baig AM, Khaleeq A, Ali U, Syeda H (2020) Evidence of the COVID-19 Virus Targeting the CNS: Tissue Distribution, Host-Virus Interaction, and Proposed Neurotropic Mechanisms. ACS Chem Neurosci; 11(7): 995-998.

38. Tian Y, Rong L, Nian W, He Y (2020) Review article: gastrointestinal features in COVID-19 and the possibility of faecal transmission. Aliment Pharmacol Ther 51(9):

\section{Epidemiology International Journal}

843-851.

39. Guan WJ, Liang WH, Zhao Y, Liang HR, Chen ZS, et al. (2020) Comorbidity and its impact on 1590 patients with Covid-19 in China: A Nationwide Analysis. Eur Respir J 55(4): 1-56.

40. Fang L, Karakiulakis G, Roth M (2020) Antihypertensive drugs and risk of COVID-19? - Authors' reply. Lancet Respir Med.

41. Patients taking ACE-i and ARBs who contract COVID-19 should continue treatment, unless otherwise advised by their physician. Statement from the American Heart Association, the Heart Failure Society of America and the American College of Cardiology. Newsroom.

42. Cequier A, Cosín J, Arrarte V, García Pinilla JM (2020) There is no clinical or scientific evidence to discontinue ACEI and ARA treatments due to COVID-19 infection. Sociedad Española de Cardiología.

43. Nacoti M, Ciocca A, Giupponi A, Brambillasca P, Lussana F, et al. (2020) At the Epicenter of the Covid-19 Pandemic and Humanitarian Crises in Italy: Changing Perspectives on Preparation and Mitigation. N Engl J Med.

44. Gawande A (2020) Keeping the Coronavirus from Infecting Health-Care Workers. What Singapore's and Hong Kong's success is teaching us about the pandemic. The New Yorker.

45. CDC (2020) Evaluating and Testing Persons for Coronavirus Disease 2019 (COVID-19).

46. Mandell, Douglas, Bennett's (2010) Principles and practice of Infectious Diseases. Philadelphia: Churchill Livingstone: $1-40$.

47. Chin J (2001) El control de las enfermedades transmisibles. Washington: OPS: 1-673.

48. Fry J (1992) Common diseases. Their nature, incidence and care. Lancaster: MTP Press Limited.

49. Paules CI, Marston HD, Fauci AS (2020) Coronavirus infections-more than just the common cold. JAMA 323(8): 707-708.

50. Spellberg B, Haddix M, Lee R (2020) Community Prevalence of SARS-CoV-2 among Patients with Influenza like Illnesses Presenting to a Los Angeles Medical Center in March. JAMA. 